Nobody can deny the value of the reviewing system as a means of deciding what to do in some practical situation - to publish or not, for example - but a research laboratory jealous of its reputation has to devise less formal, more intimate ways of forming a corporate judgement of the work its people do. The best laboratories and university departments are well-known for their searching mutual questioning. Smaller institutions are less well-placed, but are not those at which things have fallen conspicuously through the cracks. In the long run, it may be in the interests of the scientific enterprise that research people should be more dependent on the judgement of their close colleagues for the funds they can dispose of.

Palliatives such as these would not for certain make accusations of falsification disappear, however. For the unpalatable possibility must remain that even professional scientists may have more in common with other professional people - businessmen and politicians, for example - than they would like to think. Deliberate fraud in an academic setting is undoubtedly rare (and could be made even more so if universities more assiduously cultivated openness) but who could say the same of, say, unthinking or unconscious self-deception? What happens if a person finds some unexpected result in the laboratory, publishes it, wins all kinds of acclaim - and then finds that his result cannot be repeated? To say that he should instantly recant is to ask a lot of flesh and blood.

But does not such tolerance imply that dishonesty can be accepted? Of course not. There is, however, a problem of definition. To be in error is not to be disgraced. Aristotle is not scorned for having foisted a mistaken notion of mechanics on the succeeding millennium. Lord Kelvin's statue in Glasgow has not been smashed because of what he did to make the theory of the aether fashionable in the nineteenth century. But who can be sure that these errors were honest in some absolute sense, and in no whit the products of that mixture of confidence and the determination to win most simply called arrogance? To be sure, it takes extra gall to write down imagined data (and the temptation should be suppressed).

It is foolish, however, to suppose that failings such as these, regrettably common in most fields, should never occur in science. A better hypothesis would be that they should be about as commonplace as elsewhere, from which it follows that there is no way of getting rid of falsification. The best hope is that its consequences can be kept in check. In spite of the seamy record of the past few years, that seems to have been done reasonably.

\section{Research hopes fade}

\section{The promised increase of US spending on research may be illusory.}

THE euphoria with which US scientists as recently as February greeted President Reagan's 1984 budget plan, with its proposed 17 per cent increase for research and development, has not survived the spring. Since February, the House of Representatives has decided it wants to add $\$ 1,250$ million in the form of a "civilian R\&D initiative". Now the Senate is about to consider a proposal to add another $\$ 1,000$ million to the research authorizations of five major federal agencies. But in Detroit last weekend, the mood of professional budget-watchers attending the annual meeting of the American Association for the Advancement of Science (AAAS) was one of anxiety rather than opportunity. And this is not as paradoxical as it may seem: there has always been less than meets the eye to the Administration's generosity towards science. The most conspicuous deficiency of the President's spending plan is its disproportionate focus on defence research - forecast in the Administration's plan to consume more than two out of every three federal research and development dollars in 1984. Individual disciplines, too, are treated disproportionately. The bulk of the increases is to go to the physical sciences, mathematics and engineering. The medical, biological and other sciences will receive only a tiny increase or, when the full effects of inflation are computed, significant reductions.
Dr George Keyworth, the President's science adviser, makes no secret of the fact that the Administration wants to direct increases in research spending to those areas it regards as specially important. The science community, for its part, has been willing to accept that a bigger say in the selection of research priorities is part of the price the Administration will demand for a generous increase in overall spending on science. There are, however, two reasons for the new anxieties which clouded the AAAS meeting. First, it is only now becoming clear how little new money will eventually trickle through the defence structure to support basic research in the universities. And second, the nature of the research priorities selected by the Administration has raised questions about the durability of its enthusiasm for science.

Universities used to receiving basic research grants from the Department of Defense (DoD) have been complaining for several months that the money earmarked for basic research is being diverted to applied research. DoD and the Association of American Universities have taken these suspicions seriously enough to start a major investigation. At the AAAS meeting, Professor Robert Park, Washington director of the American Physical Society, drew attention to a potentially more alarming trend: the redefinition of basic research by DoD to enable a growing proportion (nearly half) of its basic reseach budget to be diverted from unsolicited research grants to a group of "new initiatives". These initiatives, he claimed, were dominated by research in areas such as "the man-machine interface"; lowspeed landing and take-off; and spacecraft survivability. If these charges are true, the outlook for the health of basic science in the universities is profoundly discouraging. It is, after all, the basic research component of the defence budget and the Department of Energy's budget for new big machines in physics that make up the bulk of the increase in spending on science under the Administration's plan. That the increase in spending is more apparent than real is a point that might well elude those including the President - who are pinning their hopes for an economic recovery on the imagined ability of basic research to stimulate high technology and spawn new industries and jobs. The great danger is that the Administration, and some in Congress, expect too great a return from too small an investment in science. When their expectations are frustrated, will the science budget be allowed to revert to its downward trend?

Congress appears to offer one source of comfort. At the very least, it can be expected to correct (but not eliminate) the Administration's disproportionate emphasis on defence in spending plans for 1984. It will also give the biomedical sciences, and the National Institutes of Health, the increases denied them in the budget. But congressional support for science cannot be taken for granted over the longer term or over the whole range of agencies and disciplines. What is clear is that non-defence research and development will face tremendous competition to sustain its share of a shrinking total for non-defence discretionary programmes.

What should the community of scientists do in the face of these dangers? First, it must make it plain to all who will listen that investment in science has to be sustained over many years before it can be expected to yield dramatic economic returns. By saying so, scientists will be accused of being ungrateful for the preferential treatment they have indeed received in the forthcoming budget. But it is far more important to scotch the notion that spending on research can be an immediate economic cure-all than it is to remain on friendly terms with a particular administration. The second challenge is to avoid the temptation to allow the present wave of enthusiasm for science spending to subvert normal procedures for allocating priorities in research. At AAAS over the weekend, several speakers were rightly critical of the unseemly scramble for congressional favour by universities and laboratories competing recently for materials research money and for the right to build the next big machine for high-energy physics. Pork-barrel politics is an effective way for the powerful to get extra money for their favourite projects. In the long run, however, science's claim on Congress is better served by adhering to the rigorous standards of peer review. 